Lugol's solution, liquor iodinii compositus. Where large masses are present applications of caustic, glacial acetic or chromic acids, Vienna paste or the galvanocautery bring about a much speedier disappearance of the growths. A bent wire applicator can be used with the aid of the laryngeal mirror or, in some cases, where the tongue can be completely depressed, no mirror need be used. Later, astringent gargles are of benefit. Cocaine is an aid in the diagnosis and also of service in the treatment.

\section{NOTE ON AN ANOMALOUS ARRANGEMENT OF THE LARGE VEINS OF THE NECK. ${ }^{1}$}

BY J. G. PINKHAM. M.D., LYNN, MAs8.

IN making an examination of the body of the young colored woman who was recently killed in Lynn, by a razor wound of the neck, an anomalous arrangement of the large veins of this region was discovered, which it seems to me worth the while to describe and place upon record. The cut began one inch in front of the angle of the jaw on the left side, and extended obliquely downwards and forwards a distance of two inches, to the top of the thyroid cartilage, thence parallel to the lower jaw on the right side, a distance of two-and-a-half inches. The structures divided were the skin, the subcutaneous cervical muscle, the superficial layer of the cervical fascia, and the sterno-hyoid muscles. The thyro-hyoid-muscle of the right side and the thyroid cartilage were cut into. At the bottom of the wound on the right side, and far out, was seen a large vein partially severed and still bleeding. From its position, this was at first supposed to be the external jugular vein; but when followed upwards with a probe it was found to divide into two main branches, one of which passed upwards and inwards to the region of the jugular foramen, and the other upwards and outwards to the front of the ear. Below, the main vein was found to dip beneath the sternocleido-mastoid muscle, and to join the subclavian, forming with it the innominate of that side. Further dissection revealed the carotid in its sheath with the pneumogastric nerve, in their usual positions, but with no vein accompanying them. It was therefore concluded that the internal jugular vein, in descending from its point of origin, had abandoned its place by the side of the internal carotid, and turning outwards towards the surface, had joined the external jugular to form a common jugular, which from this point pursued a course downwards midway between the course of the external and that of the internal jugular, until it joined the subclavian. This common jugular, although loosely invested with fibres from the cervical fascia, was entirely outside and above the sheath of the carotid. In order to make sure of $\mathrm{my}$ conclusions, I followed the bloodvessels upwards from the vena cava descendens, and laying them open verified every point. The arrangement on the left side was found to be the same as on the right, except that the vessel was smaller. As the cut was higher in the neck at this point it struck the vein in its most superficial position, and completely severed it. Had it not been for this unusual arrangement of the large veins, it is possible that the cut,'severing as it would have done, only the external jugulars, might not have 1 Read before the Massachusetts Medico-Logal Society, February 2,1887 . caused death, or at any rate might have proved less speedily fatal. As it was, death occurred from hæmorrhage in about twenty minutes, as nearly as could be ascertained, after the infliction of the wound.

\section{Ulinital Memaranda.}

\section{AN EPIDEMIC OF MEASLES. ${ }^{1}$}

BY W. D. HODGES, M.D.

AN unusual opportunity to observe an epidemic of measles at a charitable institution, from its inception to its end, is my apology for bringing this subject before the Section.

On January 27 th the iustitution contained sixtyfive children, between the ages of one and fifteen years - fortunately, a much smaller number than usual. On that day, a child six years old was admitted, and, as it had a severe cold, was sent at once to the sick ward. Twenty-four hours later an eruption appeared, which proved to be measles; and it was subsequently learned that the child had been exposed to this disease. On the same day that this child developed measles, three children were discharged from the ward in which he was put. Nine days after the discharge of one, and eleven days after the discharge of the two others, they developed measles, and had also conveyed the contagion to 14 other children, who were admitted to the hospital on the following day. Sixteen more children were taken sick on the $22 \mathrm{~d}$ and $23 \mathrm{~d}$ days after the breaking out of the first case; that is, eleven and twelve days after the development of the first set of cases. During the next seven days, that is, between the 29 th and 36 th days, 12 more children developed the disease.

Of the remaining 20 children in the institution who escaped measles, 10 were sent away: 8 had already had measles before they were inmates. In two instances, no definite information could be obtained.

The epidemic was confined to 45 children, 39 of whom were between the ages of four and seven years; and its fatality was represented by five deaths - one of whom had capillary bronchitis, and the four others diphtheria.

Examination of the throat in 30 cases showed a varying amount of congestion of the pharynx, palate, and tonsils, with, sometimes, red papules. Three cases with very marked congestion were followed, in twenty-four hours, by diphtheria, two of which were fatal.

The eruption was at its height on the fifth and sixth days, and lasted from twelve to fourteen days. In eight cases it did not disappear for over three weeks, and this group included the four oldest children, aged, respectively, nine, ten, eleven and nineteen (a servant).

It is interesting to note that two of these cases of long duration of the eruption were complicated with capillary bronchitis, one with pneumonia, and one with diphtheria. One of the children with capillary bronchitis died.

Desquamation was noticed in a large number of cases - probably more than half - in a few of which large pieces of cuticle were thrown off.

The enlargement of the glands in the neck was 1 Read before the Section for Clinical Medicine. Pathology, and
Hvgiene of the Sutfolk Iistrict Medical Society, Derember 14, jRg7. 